\title{
Three-Phase Nitrobenzene Hydrogenation over Supported Glass Fiber Catalysts: Reaction Kinetics Study
}

\author{
By Volker Höller, Dagmar Wegricht, Igor Yuranov, Lioubov Kiwi-Minsker, and Albert Renken*
}

Dedicated to Professor Dr. Manfred Baerns on the occasion of his $65^{\text {th }}$ birthday

The catalytic properties of $\mathrm{Pd}$ and Pt supported on woven glass fibers (GF) were investigated in the three-phase hydrogenation of nitrobenzene (NB). Over all catalysts, a $100 \%$ yield of aniline was attained. The catalytic activity for the best catalysts was two times higher than the activity of commercial $\mathrm{Pt} / \mathrm{C}$ catalyst traditionally used for liquid-phase hydrogenation. The intrinsic reaction kinetics were studied and a reaction scheme is suggested. The direct formation of aniline from NB was observed over Pd/ $\mathrm{GF}$ with traces of intermediates. Four intermediate products were detected during aniline formation over Pt/GF: nitrosobenzene, phenylhydroxylamine, azoxybenzene, and azobenzene. The Eley-Rideal kinetic model fits the experimental data well. The parameters of the model were determined as a function of initial NB concentration and hydrogen pressure. Pt and Pd supported on GF in woven fabrics are suggested as suitable materials for reactors with a structured catalytic bed in multiphase reactor performance.

\section{Introduction}

In the development of new catalytic multi-phase systems and the improvement of the existing systems, different aspects have to be considered, like optimal catalyst formulation, the micro- and macrostructure, lifetime, and stability to poisoning. The arrangement of the catalyst in the reactor is also an important parameter influencing the reactor performance. Conventional fixed-bed reactors are known to have drawbacks like flow maldistribution and a high pressure drop during the passage of reactants through the bed. Favorably designed flow conditions lead to uniform reactant distributions on the catalytic surface, resulting in high performance of the multiphase reactor. During the last few decades, there has been growing interest in chemical reactors with structured catalytic beds useful in three-phase reactions. Compared to traditional randomly filled fixed bed reactors, structured catalytic beds show improved fluid dynamics. This leads to better residence time distribution, allows better control of consecutive reactions, and increases product selectivity.

Honeycomb ceramic monoliths have been suggested as a suitable catalytic bed for liquid phase hydrogenation [1], oxidation of organic/inorganic compounds, and bio-reactions. These reactors offer an open macrostructure allowing high flow rates through the catalytic beds with low pressure drop and improved mass transfer properties due to the short gas diffusion distance. The main drawbacks of monolith reactors are their high costs of manufacturing and its susceptibility to thermal and mechanical shock. Moreover, the optimum performance of the monolith reactor requires uniform and stable distribution of gas and liquid over the reactor cross section, which is difficult to obtain.

[*] Dipl.-Ing. V. Höller, Dipl.-Ing. D. Wegricht, Dr. I. Yuranov, Dr. L. KiwiMinsker, and Prof. Dr. A. Renken, Laboratory of Chemical Engineering, Swiss Federal Institute of Technology Lausanne, CH-1015 Lausanne, Switzerland; e-mail: albert.renken@epfl.ch
Therefore, we suggested structured catalysts made from woven glass fiber (GF) catalytic supports as a valid alternative for the design of structured reactors [2]. These catalysts offer an open macrostructure with mechanical elasticity, are easy to handle, and are less expensive to produce than ceramic monoliths. In a previous publication [2], the catalytic properties of Pd and Pt supported on woven GF were explored for liquid phase hydrogenation of benzaldehyde as a model for three-phase catalytic reactions.

The present study is aimed at the detailed investigation of the catalytic hydrogenation of nitrobenzene (NB) over Pd/Pt supported on woven glass fibers. The catalytic NB hydrogenation is known to have a fast kinetics. Therefore, transfer phenomena will strongly influence the performance of the multiphase reactor. For the proper design of structured catalytic beds, the knowledge of the reaction scheme and the intrinsic kinetics are necessary.

\section{Experimental}

\subsection{Catalyst Preparation and Characterization}

The commercial alumoborosilicate glass (with the market specification E-type) fibers (EGF) in a woven form were used as starting materials during the catalyst preparation. These fabrics were woven from threads consisting of a bundle of filaments with a diameter of 3-10 $\mu \mathrm{m}$. GF fabrics were supplied by two manufacturers: Steklovolokno, Polotsk, Belarus type $\alpha$ and Vetrotex, France SA type $\beta$. A typical composition of these GF supports/tissues is given in Tab. 1 .

The specific surface area (SSA) of the initial GF material is $2 \mathrm{~m}^{2} / \mathrm{g}$, which corresponds to the geometric surface of the filaments. The GF fabrics were pretreated at $20{ }^{\circ} \mathrm{C}$ in $1 \mathrm{~N}$ aqueous $\mathrm{HCl}$ in order to leach out the non-silica components of the glass. By this procedure, a porous support can be obtained with a SSA up to $275 \mathrm{~m}^{2} / \mathrm{g}$. The SSA of the catalysts 
Table 1. Composition of alumoborosilicate glass fibers (GF) type $\alpha$ : Steklovolokno, Polots, Belarus and type $\beta$ : Vetrotex, France SA.

\begin{tabular}{|l|c|c|}
\hline Component & $\alpha \mathrm{GF}$, content in \%wt & $\beta \mathrm{GF}$, content in \%wt \\
\hline Silica, $\mathrm{SiO}_{2}$ & 54 & $53-55$ \\
\hline Boron oxide, $\mathrm{B}_{2} \mathrm{O}_{3}$ & 10 & $6.5-8.5$ \\
\hline Alumina, $\mathrm{Al}_{2} \mathrm{O}_{3}$ & 14.5 & $14.0-15.5$ \\
\hline $\mathrm{Calcia}, \mathrm{CaO}$ & 16.5 & $\mathbf{1}$ \\
\hline Magnesia, $\mathrm{MgO}$ & 4 & $0.5-23$ \\
\hline Iron oxide, $\mathrm{Fe}_{2} \mathrm{O}_{3}$ & 0.1 & - \\
\hline Sodium oxide, $\mathrm{Na}_{2} \mathrm{O}$ & 0.7 & - \\
\hline Flour, $\mathrm{F}$ & - & $0.2-0.6$ \\
\hline Others: $\mathrm{K}_{2} \mathrm{O}, \mathrm{F}_{2}, \mathrm{TiO}_{2}$ & 0.2 & $<2.0$ \\
\hline
\end{tabular}

used in this study was kept constant at $15 \mathrm{~m}^{2} / \mathrm{g}$ for all compositions. The SSA was measured by $\mathrm{N}_{2}$ adsorptiondesorption at $77 \mathrm{~K}$ (Sorptomatic 1990 Carlo Erba) and calculated employing the BET method.

The surface of the porous glass fibers was in some cases modified by titania $\left(\mathrm{TiO}_{2}\right)$ or alumina $\left(\mathrm{Al}_{2} \mathrm{O}_{3}\right)$. This modification was made by impregnation of the porous GF with an aqueous solution of the suitable salt followed by calcination in air at $700{ }^{\circ} \mathrm{C}$.

Palladium (II) chloride $\left(\mathrm{PdCl}_{2}\right)$ and chloroplatinic acid $\left(\mathrm{H}_{2} \mathrm{PtCl}_{6}\right.$, pure, Fluka Chemie AG, Buchs, Switzerland) were used as precursors of the active phase. The $\mathrm{Pd}$ and $\mathrm{Pt}$ supported GF catalysts were prepared by the metal deposition from aqueous $\mathrm{NH}_{3}$ solution via ion exchange [3]. The Pt compounds were decomposed in air at $400{ }^{\circ} \mathrm{C}$ for $1 \mathrm{~h}$ or alternatively reduced under an $\mathrm{H}_{2}$ atmosphere at $300{ }^{\circ} \mathrm{C}$ for $3 \mathrm{~h}$ to obtain active metals. The Pd catalysts were reduced, using a $10 \% \mathrm{wt}$ boiling sodium formate solution for $30 \mathrm{~min}$. The preparation procedure resulted in a high metal dispersion, as seen by high resolution transmission electronic microscopy (HRTEM) [2]. The metal content was kept at $0.2 \%$ wt for all catalysts.

\subsection{Experimental Set-up and Procedure}

The hydrogenation process was carried out in an isothermal 0.51 stainless steel autoclave (Büchi AG, Switzerland), which allows isothermal conditions due to a heating jacket (Fig. 1). A modified hollow stirrer was used for intensive mixing. The hydrogen was supplied at the same rate that it was consumed under isobaric reaction conditions. The samples for the analyses were drawn via a sampling tube.

The experiments were carried out using the following procedure; first, nitrobenzene (Sigma Switzerland, $99 \%$ ) was dissolved in a mixture of $91 \%$ wt of isopropanol (Fluka, $99.9 \%$ ) and $9 \%$ wt distilled water. The reactor was filled with $152 \mathrm{ml}$ solution and the solid catalyst (from 0.25 to $0.9 \mathrm{~g}$ ) was added. The catalyst was cut in small strips of 1-2 mm length to avoid mass transfer limitations. Second, the reaction was initiated by removing the air from the reactor by purging with hydrogen and stirring the solution at $1300 \mathrm{rpm}$. The temperature was controlled at $323 \mathrm{~K}$ and the hydrogen partial pressure was kept constant between 4 and 12.5 bar.

The samples were analyzed by gas chromatography (Auto System XL, Perkin Elmer) with product separation in a fused silica capillary column (30 m, Supelco Cat No 25315 Lot 3735-04B, SPB1, $0.53 \mathrm{~mm}$ ID) and a FID detector.

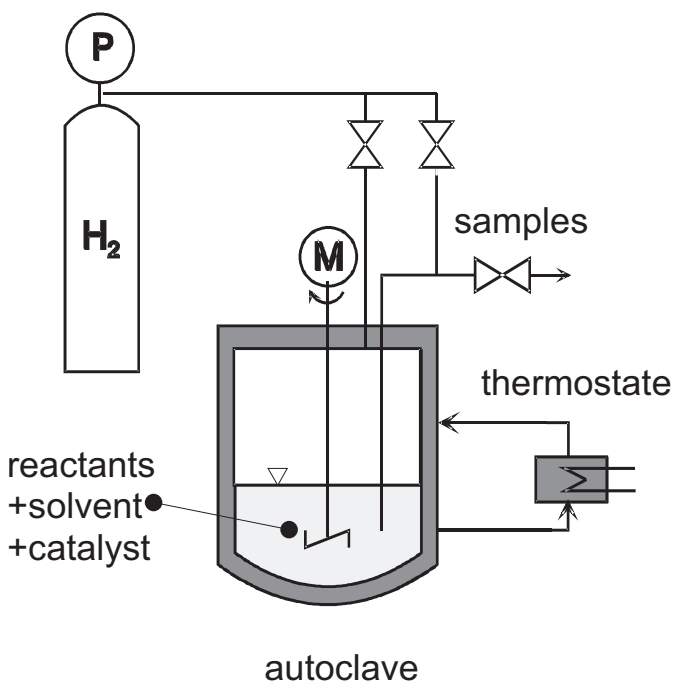

Figure 1. Experimental set-up for the liquid phase hydrogenation of nitrobenzene.

The initial reaction rate $r_{0}$ is the amount of nitrobenzene per gram of active metal and per second $\left(\mathrm{mmol}_{\mathrm{NB}} \cdot \mathrm{g}_{\mathrm{Me}}{ }^{-1} \cdot \mathrm{s}^{-1} ; \mathrm{Me}=\right.$ $\mathrm{Pd}$ or $\mathrm{Pt}$ ) and is taken as the characteristic catalytic activity. The rate is determined by fitting the experimental data using a polynomial equation and calculating the slope of this function for the reaction time $\mathrm{t}=0^{1)}$.

$\mathrm{r}_{0}=-\left.\frac{1}{\mathrm{~m}_{\mathrm{Me}}} \frac{\mathrm{dc}_{\mathrm{NB}}}{\mathrm{dt}}\right|_{\mathrm{t}=0}$

The yield $\mathrm{Y}_{\mathrm{k}}$ is calculated from

$\mathrm{Y}_{\mathrm{k}}=\frac{\mathrm{n}_{\mathrm{k}}-\mathrm{n}_{\mathrm{k}, 0}}{\mathrm{n}_{\mathrm{NB}, 0}} \frac{\nu_{\mathrm{NB}}}{\nu_{\mathrm{k}}}$

\section{Results and Discussion}

\subsection{Catalytic Selectivity and Activity}

All catalysts showed $100 \%$ selectivity towards side-chain hydrogenation, and no ring hydrogenation products were detected under the reaction conditions used.

A typical experimental result over a $\mathrm{Pd} / \mathrm{GF}$ catalyst is presented in Fig. 2. The only reaction product detected was aniline (AN). From the mass balance, the presence of some intermediates can be presumed. The maximum intermediate product concentration was assumed to be $0.01 \mathrm{~mol} \cdot \mathrm{l}^{-1}$ after $5 \mathrm{~min}$

On the contrary, over Pt/GF catalysts the formation of several intermediates was observed; nitrosobenzene (NSB), phenylhydroxylamine (PHA), azoxybenzene (AOB), and azobenzene $(\mathrm{AB})$ were detected. These intermediates are formed in several parallel and consecutive reactions as suggested in the scheme of Fig. 3 [4]. Hydrazobenzene

1) List of symbols at the end of the paper. 


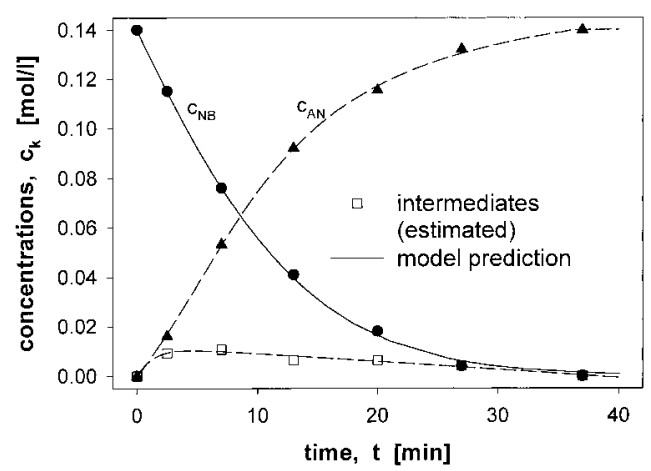

Figure 2. Concentration profiles of nitrobenzene $c_{\mathrm{NB}}$, aniline $\mathrm{c}_{\mathrm{AN}}$, and intermediates as a function of time over Pd/EGF $\beta$ - HCOONa catalysts $\left(\mathrm{m}_{\mathrm{Cat}}=0.24 \mathrm{~g} ; \mathrm{p}_{\mathrm{H} 2}=7 \mathrm{bar} ; \mathrm{k}_{\mathrm{Pd}}^{\prime}=0.74 \mathrm{~mol} \cdot\left(\mathrm{l} \cdot \mathrm{s}^{\cdot} \mathrm{g}_{\mathrm{Pt}}\right)^{-1} ; \mathrm{K}_{\mathrm{NB}, \mathrm{Pd}}=7.2(\mathrm{~mol} / \mathrm{l})^{-1}\right)$.

(HOB), which is presented in the scheme, was not observed over GF catalysts.

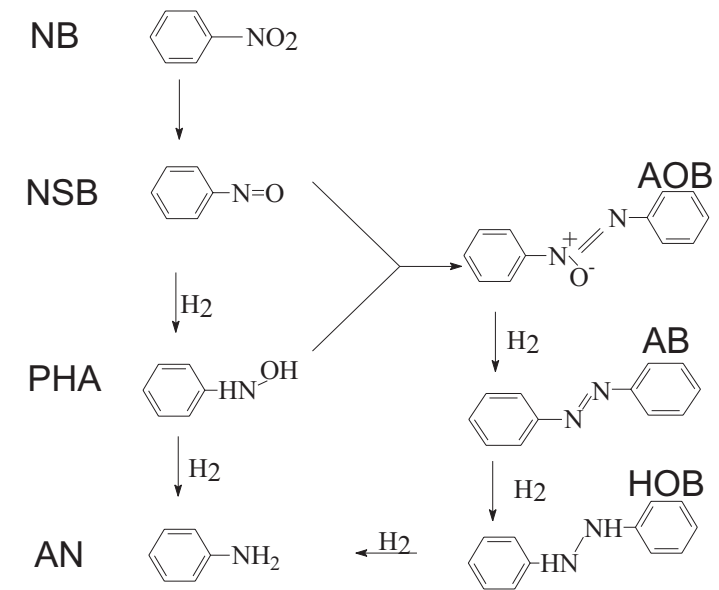

Figure 3. Reaction scheme for the selective hydrogenation of nitrobenzene [4].

The concentration profiles for a run with $\mathrm{Pt} / \mathrm{GF}$ catalyst are presented in Fig. 4. The main intermediate is NSB with a maximal yield of $30 \%$ after a reaction time of $20 \mathrm{~min}$. The highest yield of $\mathrm{AOB}$ is found to be $10 \%$ after a reaction time of $40 \mathrm{~min}$. The other intermediates (PHA and AB) show a yield of $1 \%$ or lower. The time delay between the highest concentration of NSB and that of AOB is due to the consecutive reaction of NSB with PHA to AOB (Fig. 3).

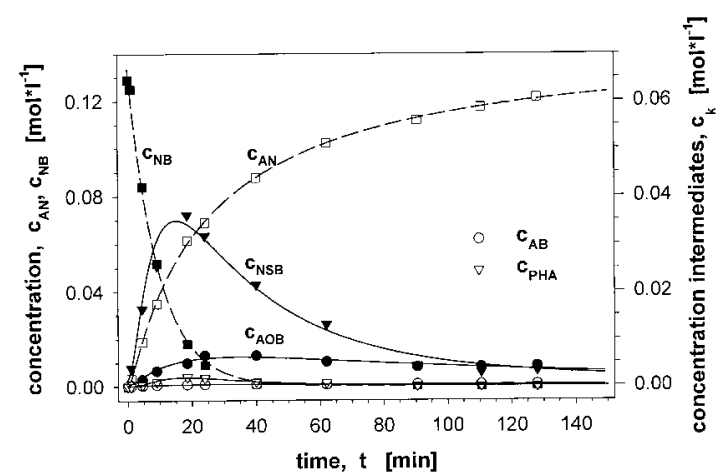

Figure 4. Measured and interpolated concentration profiles as a function of time over Pt/EGF $\beta-\mathrm{H}_{2}$ catalysts $\left(\mathrm{m}_{\mathrm{Cat}}=0.4 \mathrm{~g} ; \mathrm{p}_{\mathrm{H} 2}=7 \mathrm{bar}\right)$.
The catalytic activity was found to be strongly dependent on the type of GF support used. As can be seen from Tab. 2, the specific initial reaction rate $r_{0}$ varied over one order of magnitude.

Table 2. Comparison of activity of different catalysts in NB hydrogenation with $\mathrm{p}_{\mathrm{H} 2}$ of 7 bar.

\begin{tabular}{|l|l|l|l|l|}
\hline No. & Catalyst & GF modification & pre-treatement & initial reaction rate $\mathrm{r}_{0}$ \\
\hline & & & & mmol $_{\text {Nis }} \cdot \mathrm{g}_{\mathrm{Me}}{ }^{-1} \cdot \mathrm{s}^{-1}$ \\
\hline 1. & $\mathrm{Pd} / \mathrm{EGF} \alpha-\mathrm{HCOONa}$ & - & $\mathrm{HCOONa}$ & 4 \\
\hline 2. & $\mathrm{Pd} / \mathrm{EGF} \beta-\mathrm{HCOONa}$ & - & $\mathrm{HCOONa}$ & 45 \\
\hline 3. & $\mathrm{Pd} / \mathrm{TGF} \alpha-\mathrm{HCOONa}$ & $\mathrm{TiO}_{2}$ & $\mathrm{HCOONa}$ & 2 \\
\hline 4. & $\mathrm{Pd} / \mathrm{AGF} \alpha-\mathrm{HCOONa}$ & $\mathrm{Al}_{2} \mathrm{O}_{3}$ & $\mathrm{HCOONa}$ & 0.3 \\
\hline 5. & $\mathrm{Pt} / \mathrm{EGF} \alpha-\mathrm{H}_{2}$ & - & $\mathrm{H}_{2}$ & 17 \\
\hline 6. & $\mathrm{P} / \mathrm{EGF} \beta-\mathrm{H}_{2}$ & - & $\mathrm{H}$ & 41 \\
\hline 7. & $\mathrm{Pt} / \mathrm{EGF} \beta-\mathrm{Air}$ & - & Air & 17 \\
\hline 8. & $5 \% \mathrm{Pt} / \mathrm{C}$ (commcrcial) & - & - & 20 \\
\hline
\end{tabular}

It is interesting to note that the activities of $\mathrm{Pd}$ and $\mathrm{Pt}$ catalysts supported on glass fiber of the same type $(\mathrm{Pd} / \mathrm{EGF}-$ HCOONa and Pt/EGF $-\mathrm{H}_{2}$ ) are nearly identical and two times higher than that of a commercial Pt/C catalyst (No. 8 Johnson-Matthey, $5 \% \mathrm{Pt} / \mathrm{C}$, type 18).

The activity of both $\mathrm{Pd}$ and Pt catalysts was observed to depend on the support used. The Pd catalyst Pd/EGF $\beta$ HCOONa showed ten times higher activity compared to the $\mathrm{Pd} / \mathrm{EGF} \alpha-\mathrm{HCOONa}$ catalyst. The surface modification with titania $\mathrm{TiO}_{2}$ or aluminia $\mathrm{Al}_{2} \mathrm{O}_{3}$ led to a considerable loss of activity, probably due to the strong metal-support interactions.

For the $\mathrm{Pt} / \mathrm{GF}$ catalysts the preparation method (calcination in a flow of $\mathrm{H}_{2}$ or air) strongly influences the catalytic activity (see Tab. $2 \mathrm{Pt} / \mathrm{EGF} \beta-\mathrm{H}_{2}$ and Pt/EGF $\beta$ - Air). It can be assumed that the degree of the $\mathrm{Pt}$ reduction was higher for the pretreatment in hydrogen flow than for the catalyst calcined in air.

\subsection{Rate Equations}

In Fig. 4, a zero order dependence for high NB concentrations and a first order dependence for low NB concentrations is observed. The kinetics of the hydrogenation of NB indicates that the rate of reaction (3) follows a hyperbolic function.

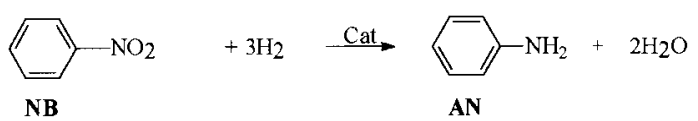

The Eley-Rideal model assumes the adsorption of NB and reaction with the non-adsorbed hydrogen molecules from the liquid phase. The reaction on the catalyst surface is the rate determining step. It follows

$$
\begin{aligned}
\mathrm{r}\left(\mathrm{c}_{\mathrm{H}_{2}}, \mathrm{c}_{\mathrm{NB}}\right) & =\mathrm{k} \frac{\mathrm{K}_{\mathrm{NB}} \cdot \mathrm{c}_{\mathrm{H}_{2}} \cdot \mathrm{c}_{\mathrm{NB}}}{1+\mathrm{K}_{\mathrm{NB}} \cdot \mathrm{c}_{\mathrm{NB}}} \\
& =\mathrm{k}^{\prime} \frac{\mathrm{K}_{\mathrm{NB}} \cdot \mathrm{c}_{\mathrm{NB}}}{1+\mathrm{K}_{\mathrm{NB}} \cdot \mathrm{c}_{\mathrm{NB}}}
\end{aligned}
$$

Eq. (5) is obtained for a constant hydrogen pressure and the term $\mathrm{k}^{\prime}$ refers to $\mathrm{k}^{\prime}=\mathrm{k}^{\cdot} \mathrm{c}_{\mathrm{H} 2}$. In order to determine the modified 
reaction constant k' and the adsorption equilibrium constant $\mathrm{K}_{\mathrm{NB}}$ from experimental data, Eq. (5) was integrated:

$\mathrm{t}=\frac{1}{\mathrm{k}^{\prime} \cdot \mathrm{K}_{\mathrm{NB}} \cdot \mathrm{m}_{\mathrm{Me}}}\left(\ln \frac{\mathrm{c}_{\mathrm{NB}, 0}}{\mathrm{c}_{\mathrm{NB}}}+\mathrm{K}_{\mathrm{NB}}\left(\mathrm{c}_{\mathrm{NB}, 0}-\mathrm{c}_{\mathrm{NB}}\right)\right)$

The constants k' and $\mathrm{K}_{\mathrm{NB}}$ were optimized by minimizing the root mean square values of the NB concentrations.

The experimental results and the modeling for the NB hydrogenation over a Pd/EGF $\beta-\mathrm{HCOONa}$ catalyst are shown in Fig. 2. The experimental data (points) as well as the modeling of the NB profile (line) are shown. A modified reaction constant $\mathrm{k}_{\mathrm{Pd}}{ }_{\mathrm{O}}$ of $0.74 \mathrm{~mol} \cdot\left(\mathrm{l} \cdot \mathrm{s} \cdot \mathrm{g}_{\mathrm{Pt}}\right)^{-1}$ and an adsorption equilibrium constant $\mathrm{K}_{\mathrm{NB}, \mathrm{Pd}}$ of $7.2(\mathrm{~mol} / \mathrm{l})^{1}$ were obtained.

A more detailed kinetics study was carried out using a Pt/ EGF $\beta-\mathrm{H}_{2}$ catalyst. Therefore, three experiments with three different initial NB concentrations, as shown in Fig. 5, were taken into account. The two model parameters were fitted simultaneously to the experimental results, leading to a reaction constant $\mathrm{k}_{\mathrm{Pt}, \mathrm{H} 2}^{\prime}$ of $0.31 \mathrm{~mol} \cdot\left(\mathrm{l} \cdot \mathrm{s} \cdot \mathrm{g}_{\mathrm{Pt}}\right)^{-1}$ and an adsorption equilibrium constant $\mathrm{K}_{\mathrm{NB}, \mathrm{Pt}, \mathrm{H} 2}$ of $7.0(\mathrm{~mol} / \mathrm{l})^{1}$. A remarkably high reproducibility of the experimental data is obvious.

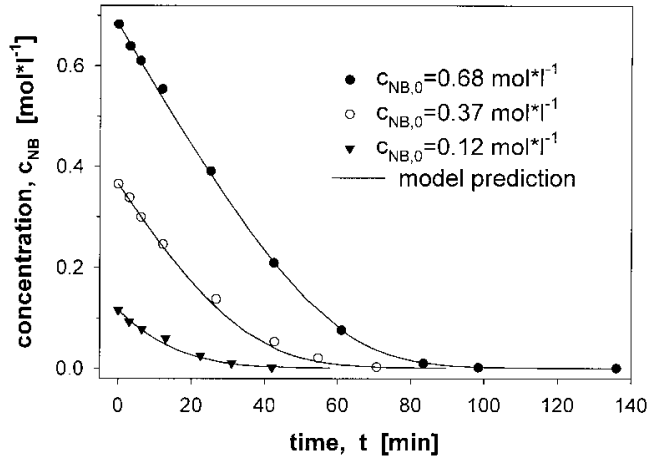

Figure 5. Measured and calculated nitrobenzene concentration $\mathrm{c}_{\mathrm{NB}}$ profiles as a function of time $\left(\mathrm{Pt} / \mathrm{EGF} \beta-\mathrm{H}_{2} ; \mathrm{m}_{\mathrm{Cat}}=0.4 \mathrm{~g} ; \mathrm{p}_{\mathrm{H} 2}=7 \mathrm{bar}\right.$; $\left.\mathrm{k}_{\mathrm{Pt}, \mathrm{H} 2}^{\prime}=0.31 \mathrm{~mol} \cdot\left(1 \cdot \mathrm{g}_{\mathrm{Pt}}\right)^{-1} ; \mathrm{K}_{\mathrm{NB}, \mathrm{Pt}, \mathrm{H} 2}=7.0(\mathrm{~mol} / \mathrm{l})^{-1}\right)$.

Eq. (4) shows a linear dependency of the reaction rate on the hydrogen concentration. The Eley-Rideal model assumes no influence of the non-adsorbed hydrogen molecules on the adsorbed NB molecules. Therefore, the adsorption equilibrium constant $\mathrm{K}_{\mathrm{NB}}$ is constant for different hydrogen concentrations. To confirm the pressure dependence of the Eley-Rideal model, the experiments with four different hydrogen pressures $\mathrm{p}_{\mathrm{H} 2}(4,7,10$, and 12.5 bar) over $\mathrm{Pt} / \mathrm{EGF} \beta$-Air catalysts were carried out. The results are presented in Fig. 6, while Fig. 7 shows the modified reaction constant $\mathrm{k}_{\text {Pt,Air }}$ as a function of the hydrogen pressure. The linear regression line illustrates that the pressure dependence fits the Eley-Rideal equation. That the trend line does not tend to intercept at zero is in agreement with the experimental results obtained by Tong et al. [5]. The reaction rate was observed to increase sharply for low hydrogen pressures and slowly for higher partial hydrogen pressures.

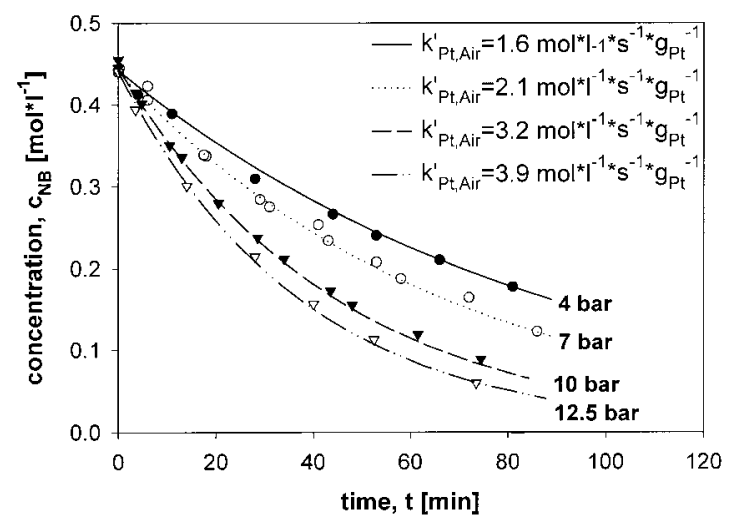

Figure 6. Measured and calculated concentration profiles of nitrobenzene $c_{\mathrm{NB}}$ as a function of time and hydrogen partial pressure $\mathrm{p}_{\mathrm{H} 2}(\mathrm{Pt} / \mathrm{EGF} \beta-\mathrm{Air}$; $\left.\mathrm{K}_{\mathrm{NB}, \mathrm{Pt}}=0.15(\mathrm{~mol} / \mathrm{l})^{-1}\right)$.

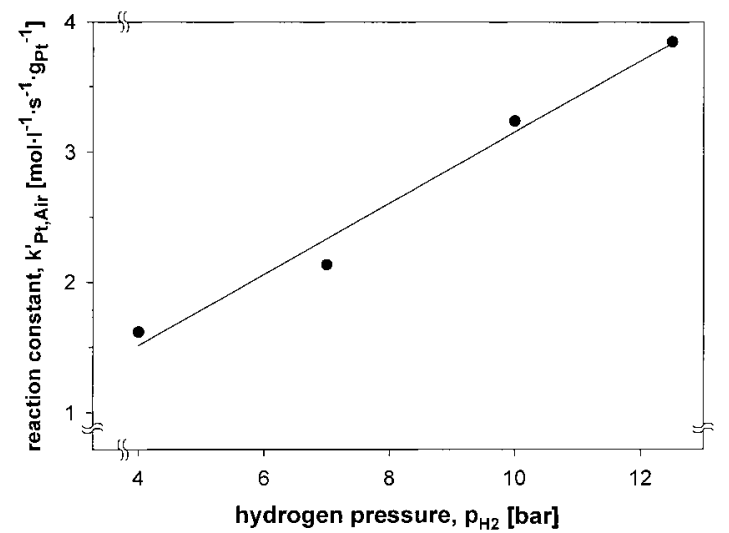

Figure 7. Modified reaction constant $\mathrm{k}_{\mathrm{Pt}, \mathrm{Air}}^{\prime}$ as a function of the hydrogen pressure $\mathrm{p}_{\mathrm{H} 2}\left(\mathrm{Pt} / \mathrm{EGF} \beta-\mathrm{Air} ; \mathrm{m}_{\mathrm{Cat}}=0.4 \mathrm{~g} ; \mathrm{c}_{\mathrm{NB}, 0}=0.44 \mathrm{~mol} \cdot \mathrm{1}^{1}\right.$; $\left.\mathrm{K}_{\mathrm{NB}, \mathrm{Pt}}=0.15(\mathrm{~mol} / \mathrm{l})^{-1}\right)$.

The different values for the parameter $\mathrm{k}_{\mathrm{Pt}}$ and $\mathrm{K}_{\mathrm{NB}, \mathrm{Pt}}$ reported in Figs. 5 and 6 reflect the different activities of the used catalysts $\mathrm{Pt} / \mathrm{EGF} \beta-\mathrm{H}_{2}$ and $\mathrm{Pt} / \mathrm{EGF} \beta-$ Air.

\section{Conclusions}

$\mathrm{Pd}$ and Pt supported on GF are active catalysts in liquid phase hydrogenation of NB with a $100 \%$ yield of aniline.

The activity depends on the type of GF support, chemical modification of the support surface, and the method of catalyst activation. The best samples were two times more active than the standard commercial $\mathrm{Pt} / \mathrm{C}$ catalyst.

The Eley-Rideal mechanism described the experimental data. The two parameters of the model $\left(\mathrm{K}_{\mathrm{NB}}-\right.$ equilibrium constant of adsorption of nitrobenzene, k'- modified rate constant) were determined for different NB initial concentrations at different hydrogen pressures.

$\mathrm{Pt}$ and Pd supported on GF in woven fabrics are suitable catalysts for the structured reactor design useful for multiphase reaction operation. 


\section{Acknowledgment}

The financial support provided for this work by the Swiss National Foundation and the Max-Buchner-Forschungsstiftung is gratefully acknowledged. The authors also would like to thank Prof. G. Emig and Prof. V. Barelko for fruitful discussions.

Received: July 12, 1999 [CET 1140]

\section{Symbols used}

\begin{tabular}{|c|c|c|}
\hline$c_{k}$ & {$\left[\mathrm{~mol} \cdot \mathrm{l}^{-1}\right]$} & concentration of component $\mathrm{k}$ \\
\hline $\mathrm{k}_{\mathrm{i}}$ & {$\left[\mathrm{g}_{\mathrm{Me}}{ }^{-1} \cdot \mathrm{s}^{-1}\right]$} & rate constant for catalyst $\mathrm{i}$ \\
\hline $\mathrm{k}_{\mathrm{i}}{ }^{\prime}$ & {$\left[\mathrm{mol} \cdot \mathrm{g}_{\mathrm{Me}}{ }^{-1} \cdot \mathrm{s}^{-1} \cdot \mathrm{l}^{-1}\right]$} & modified rate constant for catalyst $i$ \\
\hline $\mathrm{K}_{\mathrm{NB}, \mathrm{i}}$ & {$\left[1 \cdot \mathrm{mol}^{-1}\right]$} & $\begin{array}{l}\text { equilibrium constant of adsorption } \\
\text { of nitrobenzene for catalyst } i\end{array}$ \\
\hline $\mathrm{m}_{\mathrm{Me}}$ & [g] & mass of catalytic active metal \\
\hline $\mathrm{n}_{\mathrm{k}}$ & {$[\mathrm{mol}]$} & amount of component $\mathrm{k}$ \\
\hline $\mathrm{p}_{\mathrm{H} 2}$ & [bar] & partial pressure of hydrogen \\
\hline r & {$\left[\mathrm{mol} \cdot \mathrm{g}_{\mathrm{Me}}{ }^{-1} \cdot \mathrm{s}^{-1} \cdot \mathrm{l}^{-1}\right]$} & rate constant \\
\hline $\mathrm{r}_{0}$ & {$\left[\mathrm{~mol} \cdot \mathrm{g}_{\mathrm{Me}}{ }^{-1} \cdot \mathrm{s}^{-1} \cdot \mathrm{l}^{-1}\right]$} & initial rate constant \\
\hline $\mathrm{t}$ & {$[\mathrm{s}]$ or $[\mathrm{min}]$} & time \\
\hline
\end{tabular}

\section{Greek symbols}

$\alpha \quad$ glass fiber manufacturer Steklovokno, Belarus

$\beta \quad$ glass fiber manufacturer Vetrotex, France

$\nu \quad$ stoichiometric coefficient

\section{Subscripts}

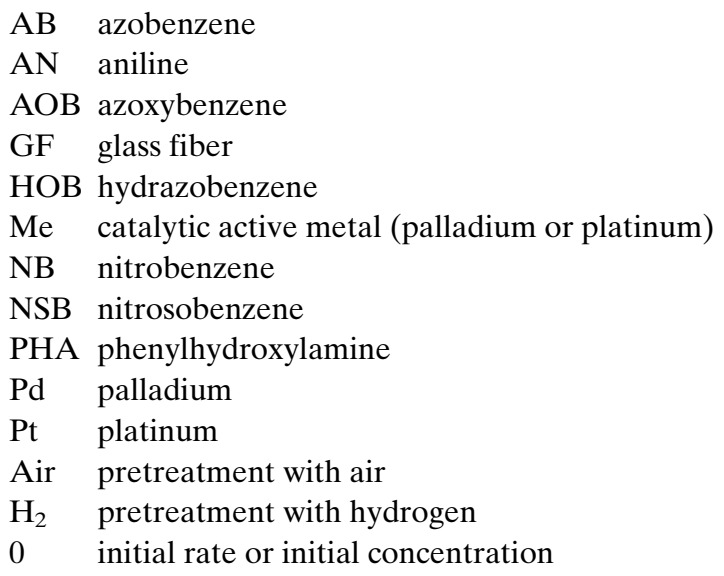

\section{References}

[1] Hatzlantonlou V.; Andersson B.; Schöön N. H., Ind. Eng. Chem. Process Des. Dev. 25 (1986) pp. 964-970.

[2] Kiwi-Minsker L.; Yuranov I.; Höller V.; Renken A., Chem. Eng. Sci. 54 (1999) pp. 4785-4790.

[3] Neyestanaki A.K.; Lindfors L.-E., Combust. Sci. and Techn. 110-111 (1995) pp. $303 \mathrm{ff}$.

[4] Ertl G.; Knötzinger H.; Weitkamp J., Handbook of Heterogeneous Catalysis, Wiley-VCH, Weinheim 1997, Vol.V.

[5] Tong S. B.; O’Driscoll F. K.; Rempel G. L., Can. J. Chem. Eng. 56 (1978), pp. 340-345. 